http://jmscr.igmpublication.org/home/ ISSN (e)-2347-176x ISSN (p) 2455-0450

crossref DOI: https://dx.doi.org/10.18535/jmscr/v8i2.07

Journal Of Medical Science And Clinical Research

\title{
Study of Clinical and Biochemical Profile in Neonatal Seizure in a tertiary care centre of Jharkhand
}

\author{
Authors \\ Dilip Kumar ${ }^{1}$, Rajeeva Mishra $^{2}$, Gora Chand $^{3}$, Sweety Kumari ${ }^{4}$ \\ ${ }^{1}$ Junior Resident, Department of Paediatrics and Neonatology, RIMS, Ranchi \\ ${ }^{2}$ Professor, Department of Paediatrics and Neonatology, RIMS, Ranchi \\ ${ }^{3}$ Junior Resident, Department of Paediatrics and Neonatology, RIMS, Ranchi \\ ${ }^{4}$ Junior Resident, Department of Obstetrics and Gynaecology, RIMS, Ranchi \\ *Corresponding Author \\ Dilip Kumar \\ Junior Resident, Department of Paediatrics and Neonatology, RIMS, Ranchi, India
}

\begin{abstract}
Background: Neonatal seizures are one of the most common and distinctive clinical manifestations of dysfunction of neurological system. Neonatal seizures represent responses of the immature nervous system to varied insults resulting in considerable neonatal mortality and morbidity including motor and cognitive disabilities in the childhood. Neonatal seizures are more common in preterm compared to term neonates and metabolic abnormalities are common cause of neonatal seizure.

Objectives: Current study aims at to study: 1. the incidence of biochemical abnormalities associated with neonatal seizure \& 2. The clinical presentation, time of onset and its relation to the neonatal seizures.

Methods: A prospective hospital based study was conducted for a period of 6 months from May 2017 to November 2017, a total of 80 newborns with seizure were enrolled in the study after taking complete history and appropriate physical examination. Blood sample was collected for detecting metabolic abnormalities before instituting specific therapy.

Results: In my study, neonatal seizure occurred more commonly in term babies especially in appropriate for gestational age babies compared to preterm neonates. There was a male predominance. Most seizures are due to intramural deliveries and occurred within 72 hours of life. Seizures are more common in babies with birth weight $\geq 2.5 \mathrm{~kg}$ and subtle seizure is the most common type. The most common biochemical abnormality noted was hypoglycemia (40\%) and hypocalcemia (32\%). There were cases reported with combination of hypoglycemia / hypocalcemia and hypocalcemia/hypomagnesemia particularly in preterm but their incidence is low.

Conclusion: The transient metabolic abnormalities are easily treatable when identified early and are associated with good prognosis. Hence biochemical work up should be done in all neonates with seizure and should be included as the first line of investigation in all cases, thereby preventing the further occurrence of seizure and overuse of anticonvulsants. It also improve the prognosis and outcome of the neonate and prevent the long term neurological sequelae associated with it.

Keywords: Neonatal seizure, hypoglycemia, hypocalcemia.
\end{abstract}




\section{Introduction}

Neonatal seizures are one of the most common and distinctive clinical manifestations of dysfunction of neurological system. Neonatal seizures represent non specific responses of the immature nervous system to varied insults and results in considerable neonatal mortality and long term morbidity including motor and cognitive disabilities in the childhood ${ }^{[1,2]}$. Neonatal seizures are often under-recognized, and difficult to treat. Hence it is critical to recognize seizures early and initiate immediate therapy.

Recognition of etiology is often helpful in prognosis and treatment. Studies suggest that neonatal seizures and their etiology have a significant impact on developing brain; however, in clinical practice at neonatal intensive care unit (NICU), in developing countries where synchronized video-EEG monitoring is practically non-existent, clinical observation becomes the key to the diagnosis ${ }^{[3]}$.

Hence we undertook this study in our centre where continuous video-EEG monitoring is not possible to identify neonatal seizures, thereby applying clinical criteria and also to find out the biochemical abnormalities associated with these clinical seizures.

\section{Methods}

This study was a hospital based prospective observational study conducted over a period of 6 months from May 2017 to November 2017 in the department of Paediatrics and neonatology, Rajendra institute of medical Sciences, Ranchi. A total of 80 neonates (birth to 28 days of life), all term and preterm, presenting with seizures admitted to the neonatal unit of Department of Paediatrics in Rajendra institute of medical sciences were included. Detailed antenatal history and baseline characteristics of all the babies noted which includes name, age, sex, address, weight, length, head circumference, gestational age. Thorough physical examination was done and seizures were diagnosed by clinical observation. Clinical details of each seizure episode were recorded like age at onset of seizures, duration of seizure, number and type of seizure. Seizure were classified into subtle, focal clonic, multifocal clonic, tonic and myoclonic as per criteria by Volpe.

\section{Exclusion Criteria}

1. Baby already on anticonvulsant therapy.

2. Mothers or caregivers not giving consent for the study.

Following investigations was done before initiating treatment:

1. Blood glucose.

2. Total serum calcium level.

3. Serum sodium level.

4. Serum magnesium level.

5. Serum potassium level.

Criteria for diagnosing various biochemical abnormalities:

1. Hyponatremia: $\quad<135 \mathrm{mEq} / \mathrm{l}$

2. Hypernatremia: $>145 \mathrm{mEq} / 1$

3. Hypoglycaemia: $<40 \mathrm{mEq} / \mathrm{dl}$ (capillary blood) $<45 \mathrm{mEq} / \mathrm{dl}$ (venous blood)

4. Hypocalcemia: $<7 \mathrm{mg} / \mathrm{dl}$ for preterm neonates $<8 \mathrm{mg} / \mathrm{dl}$ for term neonates

5. Hypomagnesemia: $<1.5 \mathrm{mg} / \mathrm{dl}$

6. Hypermagnesemia: $>2.5 \mathrm{mg} / \mathrm{dl}$

7. Hypokalemia: $<3.5 \mathrm{mg} / \mathrm{dl}$

8. Hyperkalemia: $\quad>5.5 \mathrm{mg} / \mathrm{dl}$.

\section{Results}

A total of 80 neonates were included in this study. Among them 37 were delivered by normal vaginal delivery, 37 neonates were delivered by caserean section and 6 by forceps delivery. Among the study population :

1. The number of babies born within institution was 65 and number referred from outside was 15 .

2. The Preterm were 23 and term were 57 and there were no post-term.

3. The male were 45 and female were 35 .

4. The babies with low birth weight $(<2.5 \mathrm{~kg})$ were $34(42.5 \%)$ and Normal Birth weight $(\geq 2.5 \mathrm{~kg})$ were $46(57.5 \%)$. 
5. the onset of seizures within 24 hours, day 1 to 3 , day 4 to 7 , and $>7$ days were 23 (28.75\%), 35 (43.75\%), $16 \quad(20.00 \%)$ and $6 \quad(7.5 \%)$ respectively. Convulsions in the first 3 days contributes to $72.5 \%$.

Table-1: Descriptive analysis of type of seizures in study population

\begin{tabular}{|c|c|c|}
\hline Type of Seizure & Number & Percentages \\
\hline Subtle & 49 & $61.25 \%$ \\
\hline Tonic & 20 & $25.00 \%$ \\
\hline Clonic & 11 & $13.75 \%$ \\
\hline
\end{tabular}

Table-2: Descriptive analysis of Hypoglycemia in study population

\begin{tabular}{|c|c|c|}
\hline Hypoglycemia & Number & Percentages \\
\hline Present & 20 & $25 \%$ \\
\hline Absent & 60 & $75 \%$ \\
\hline
\end{tabular}

Table-3: Descriptive analysis of Hypocalcemia in study population

\begin{tabular}{|c|c|c|}
\hline Hypocalcemia & Number & Percentages \\
\hline Present & 16 & $20 \%$ \\
\hline Absent & 64 & $80 \%$ \\
\hline
\end{tabular}

Table-4: Descriptive analysis of Hyponatremia in study population

\begin{tabular}{|c|c|c|}
\hline Hyponatremia & Number & Percentages \\
\hline Present & 07 & $8.75 \%$ \\
\hline Absent & 73 & $91.25 \%$ \\
\hline
\end{tabular}

Table-5:

Descriptive

analysis

of

Hypomagnesemia in study population

\begin{tabular}{|c|c|c|}
\hline Hypomagnesemia & Number & Percentages \\
\hline Present & 04 & $5.00 \%$ \\
\hline Absent & 76 & $95.00 \%$ \\
\hline
\end{tabular}

Table-6: Descriptive analysis of Hypernatremia in study population

\begin{tabular}{|c|c|c|}
\hline Hypernatremia & Number & Percentages \\
\hline Present & 03 & $3.75 \%$ \\
\hline Absent & 77 & $96.25 \%$ \\
\hline
\end{tabular}

Table-7: Descriptive analysis of combination in study population.

\begin{tabular}{|c|c|c|}
\hline Combination of & Number & Percentages \\
\hline $\begin{array}{c}\text { Hypoglycemia \& } \\
\text { Hypocalcemia }\end{array}$ & 03 & $3.75 \%$ \\
\hline $\begin{array}{c}\text { Hypocalcemia \& } \\
\text { Hypomagnesemia }\end{array}$ & 01 & $1.25 \%$ \\
\hline
\end{tabular}

Table-8: Association of TERM/ PRETERM with Variables of study population

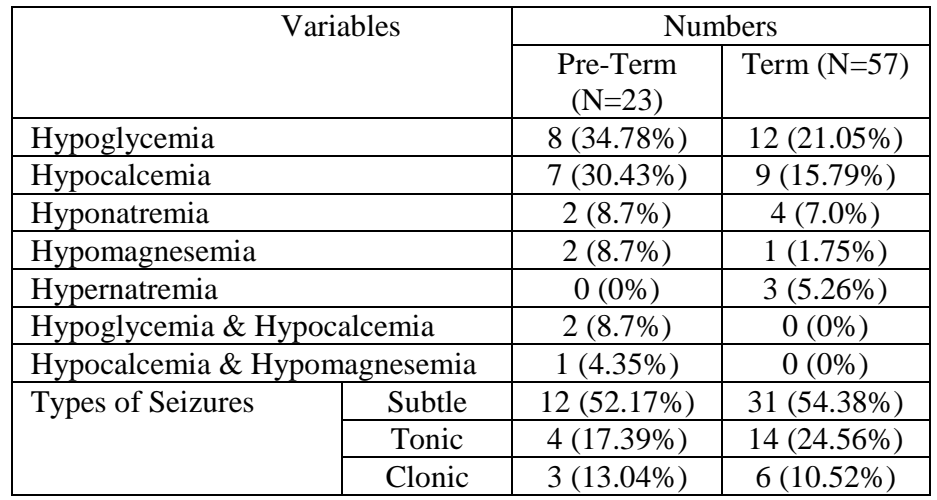

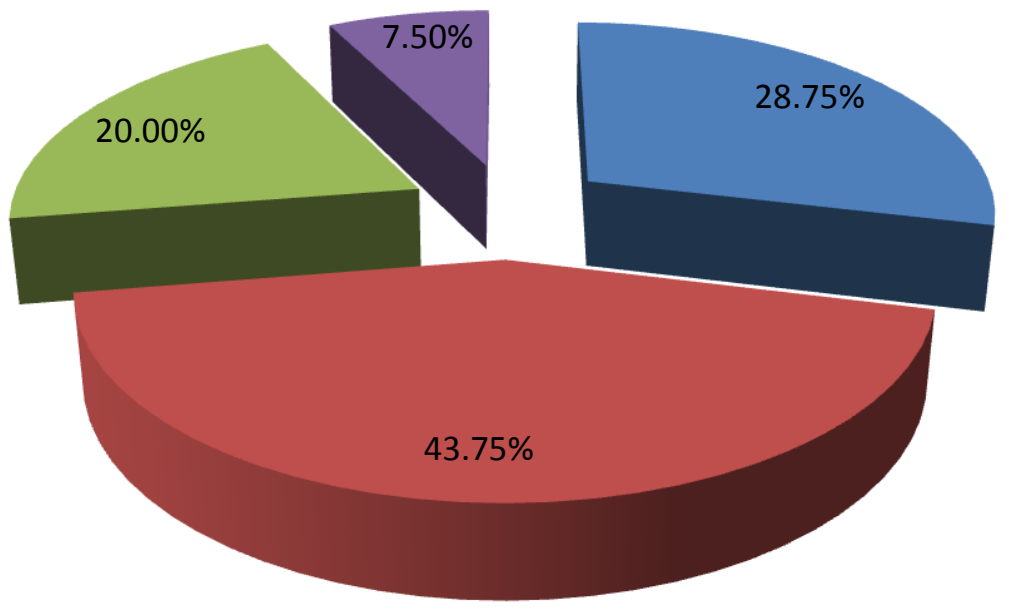

$<1$ Days

1 - 3 Days

4 - 7 Days

- 7 Days

Fig-1: Percentages of Days of Onset of Seizures 


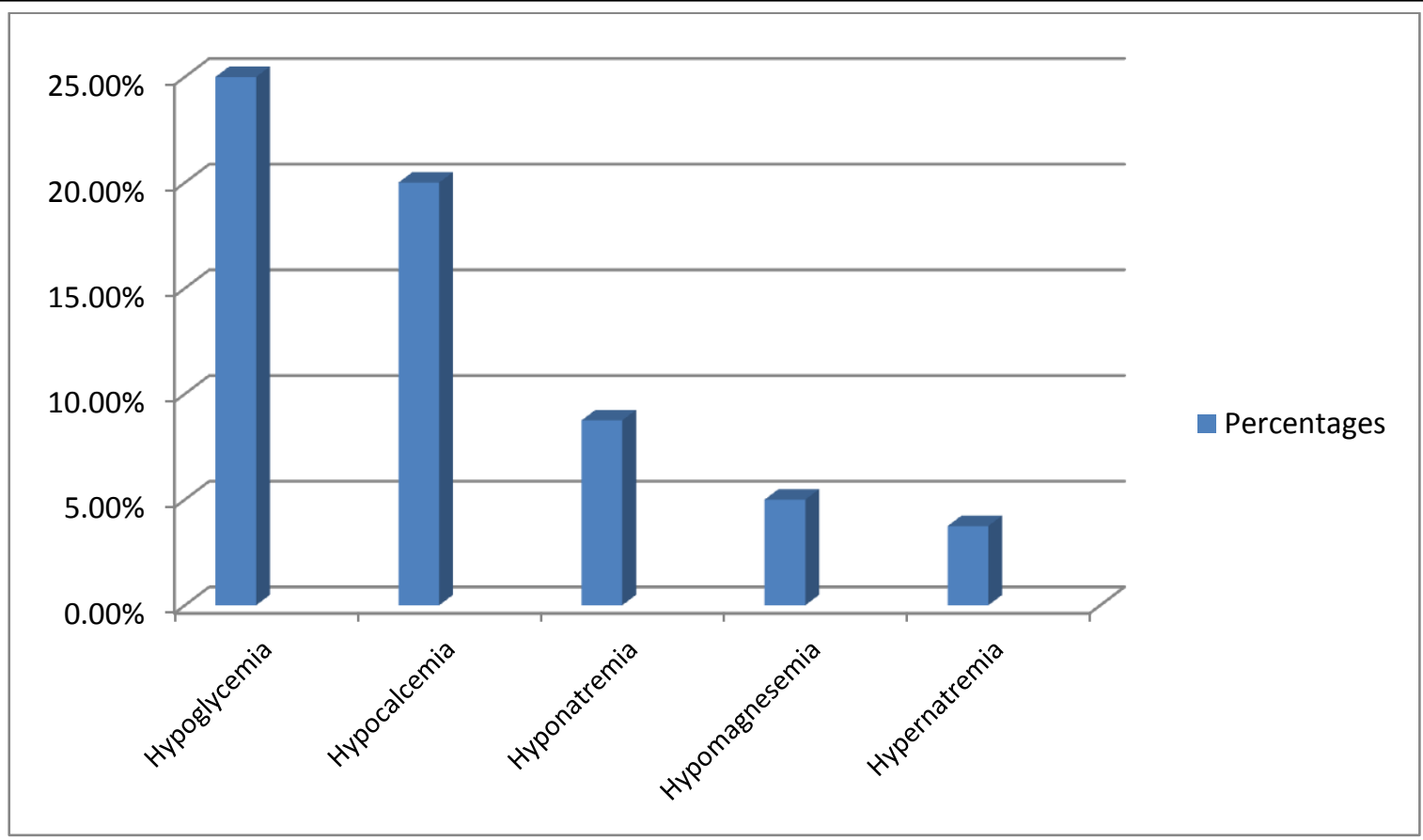

Fig-2: Summary of various biochemical abnormalities in study population.

\section{Discussion}

Seizures are most common neurological disorders in newborn which are more prevalent in preterm neonates compared to term neonates. Out of 80 neonates, full term neonates were 57 and preterm constitutes 23 in number. Majority of neonates with seizures in my study were full term neonates. Similar observation were seen in study by Aziz et $\mathrm{al}^{[4]}$ where term babies constitutes $65 \%$ and preterm 35\%. In studies by Park Weon et $\mathrm{al}^{[5]}$ and Dinesh Das et $\mathrm{al}^{[6]}$,they also reported a much higher incidence in term babies compared to preterm neonates.

In my study, neonatal seizures were common in male babies contributing about $56.25 \%$ and female about $43.75 \%$, similar to study done by Aziz et $\mathrm{al}^{[4]}$ (male $60 \%$, female $40 \%$ ) and Dinesh Das et al ${ }^{[6]}$ (male $62.6 \%$, female $37.4 \%$ ) also reported male predominance.

In my studies, 37 babies ( $46.25 \%)$ born by normal vaginal delivery, 37 ( $46.25 \%$ ) by caserean section and $6(7.5 \%)$ babies by forceps delivery. Aziz et $\mathrm{al}^{[4]}$ in his study reported neonates with seizures born by normal vaginal delivery $48 \%$, by caserean $28 \%$ and operated vaginal $24 \%$.

In my study, 46 neonates $(57.5 \%)$ had birth weight $\geq 2.5 \mathrm{~kg}$ and 34 neonates $(42.5 \%)$ had birth weight $<2.5 \mathrm{~kg}$ similar observations were made by Dinesh Das et $\mathrm{al}^{[6]}$ where neonates $>2.5 \mathrm{~kg}$ were $65 \%$ and $<2.5 \mathrm{~kg}$ were $35 \%$ respectively.

Out of 80 neonates in my studies 23 had seizures within 24 hours $(28.75 \%), 35$ neonates between 24-72 hours (43.75\%), 16 babies between day 4 to $7(20.00 \%)$ and 6 babies above 7 days (7.5\%). Thus most of the seizures occurred within 3 days of life contributing about $72.5 \%$ similar to observations made by Dinesh Das et $\mathrm{al}^{[6]}$ and Nawab et $\mathrm{al}^{[7]}$ where seizures within 3 days was $71.3 \%$ and $73.6 \%$ respectively.

The most common type of neonatal seizures in our study was subtle contributing about $61.25 \%$ in about 49 neonates, followed by tonic seizures in $25.00 \%$ (20) and clonic $13.75 \%$ (11), similar to findings of Sudia et $\mathrm{al}^{[8]}$ and Dinesh Das et $\mathrm{al}^{[6]}$ where subtle seizures occurred in $63.33 \%$ and $42.6 \%$,tonic seizures $19.33 \%$ and $33.9 \%$, clonic in $10 \%$ and $15.7 \%$ respectively.

Out of 80 neonates, 50 babies with seizures had one or more biochemical abnormality contributing to about $62.5 \%$ in total. Sood et al ${ }^{[9]}$ in his study overall biochemical abnormalities in 29 cases $(49.15 \%)$ comparable to my study. Similar observation were made by Nawab et $\mathrm{al}^{[7]}$ in his studies where out of 110 neonates, 46 babies had 
biochemical abnormality contributing to $41.8 \%$. Kumar et $\mathrm{al}^{[10]}$ has found overall biochemical abnormalities in $62.8 \%$ of neonates against Madhusudan et $\mathrm{al}^{[11]} 43.33 \%$.

Comparison of most common biochemical abnormalities in neonatal seizures as reported by various authors:

\begin{tabular}{|l|c|c|c|c|}
\hline $\begin{array}{l}\text { Biochemical } \\
\text { abnormalities } \\
\text { (overall) }\end{array}$ & $\begin{array}{c}\text { KUMAR } \\
1995\end{array}$ & $\begin{array}{c}\text { ARVIND SOOD } \\
\text { N }=35\end{array}$ & $\begin{array}{c}\text { MADHUSUDAN } \\
\mathrm{N}=59\end{array}$ & $\begin{array}{c}\text { PRESENT STUDY } \\
\mathrm{N}=120\end{array}$ \\
\hline Present & $22(62.8 \%)$ & $29(49.15 \%)$ & $52(43.33 \%)$ & $\mathrm{N}=80$ \\
\hline Absent & $13(37.2 \%)$ & $30(50.85 \%)$ & $68(56.66 \%)$ & $30(62.5 \%)$ \\
\hline Total & $35(100 \%)$ & $59(100 \%)$ & $120(100 \%)$ & $80(100 \%)$ \\
\hline
\end{tabular}

The most common biochemical abnormality in my study was hypoglycaemia followed by hypocalcemia particularly in preterm neonates. Among preterm babies the incidence of hypoglycaemia were $34.78 \%$ compared to $21.05 \%$ in term babies. Hypocalcemia was reported in $30.43 \%$ among preterm babies which was higher when compared with term babies about $15.79 \%$. Suganthi et $\mathrm{al}^{[12]}$ in her study has made similar observation where Metabolic abnormalities were present in $89(59.3 \%)$ out of 150 cases. Of these hypoglycaemia and hypocalcemia were the most common with 39 $(48.8 \%)$ and $28(35.4 \%)$ cases respectively. Sameer kumar jain et $\mathrm{al}^{[13]}$, Shah et $\mathrm{al}^{[14]}$ and Iype maya Prasad et $\mathrm{al}^{[15]}$ also found hypoglycaemia followed by hypocalcemia to be most common metabolic disturbances in their study further supporting my finding.

\section{Conclusion}

Neonatal seizures are one of the most common neurological problems in neonates. There are various causes for neonatal seizures which not only determines the course of the disease but also helps in determining its associated long term neurological outcome along with morbidity and mortality. Quick assessment, timely diagnosis and aggressive management according to the etiology are necessary to prevent these problems. Moreover biochemical abnormalities may either occur as a primary problem or may be associated with other etiologies.

These transient abnormalities are easily treatable when identified early and are associated with good prognosis. Hence biochemical work should be done in all neonates with seizures and should be included as the first line investigation in all cases. Early correction of these biochemical abnormalities help in preventing the further occurrence of seizures and also help in avoiding overuse of anticonvulsants which may be unnecessary in some cases. Further early correction of these metabolic abnormality improve the prognosis and outcome of the neonate and also prevent the long term neurological sequelae associated with it.

Wherever possible continuous video-EEG monitoring should be included in identifying the neonatal seizures to know the real magnitude of the problem and to treat these seizures promptly.

\section{References}

1. Miller SP, WeissJ, BarnwallA, Ferriero DM, Latal HB, Ferrer RA et al. Seizure associated brain injury in term newborn with perinatal asphyxia. Neurology. 2002;58(4):542-8.

2. Davis AS, Hintz SR, Van KP, LiL, Das A, Stoll BJ et al. Seizure in extremely low birth weight infants are associated with adverse outcome.JPediatr.2010;157(5):720-5.

3. Holanda MRR, Melo AN. Comperative clinical study of preterm and full term newborn neonatal seizures. Arq Neuropsiquiatr2006;64:282-8.

4. Aziz A. Gattoo, M Aziz, G Rasool. Clinical and etiological profile of neonatal seizures: A tertiary care hospital based study Int J Res Med Sci.2015 Sep;3(9):2198-2203. 
5. Park, Weon et al. "Clinical study of neonatal seizure." Journal of the Korean Child Neurology Society6.1(1998):71-82.

6. Das, Dinesh and Sanjib Kumar Debbarma. "A study on clinic-Biochemical Profile of Neonatal Seizure." Journal of Neurology Research6.5-6(2016):95-101.

7. Nawab T, Lakshmipathy NS. Clinical profile of neonatal seizures with special reference to biochemical abnormalities. Int J ContempPediatr2016;3:183-8.

8. Sudia, Sanjeev et al. "Clinicoetiological profile and outcome of neonatal seizures." International Journal of Contemporary Pediatrics2.4(2017):389-394.

9. Sood A, Grover N, Sharma R. Biochemical abnormalities in neonatal seizures. Indian Journal of Paed.2003; 70(3):221-4.

10. Kumar A, Gupta V, Kachhawaha JS, Singla PN. Biochemical abnormalities in neonatal seizures. Indian Pediatr.1995;32(4):424-428.

11. Madhusudan K, Nadavapali Suresh S, Babu TR, Rao JV, Kumar S B. Study of biochemical abnormalities in neonatal seizures with special reference to hyponatremia. Int $\mathbf{J}$ Contemp Pediatr 2016;3:730-4.

12. Suganthi V, Vikneshwari K, Thivya G. Prevalence of hypomagnesemia in neonatal seizures in a tertiary care hospital in South India. J Pediatr Res.2017; 4(01):64-68.doi:10.17511 /ijpr.2017.01.13.

13. Sameer Kumar Jain. Study of the clinical profile of neonatal seizures. June 2015;2(6):336-338.

14. Shah, G. S. et al. " Clinico-Biochemical profile of neonatal seizure." Journal of Nepal Paediatric Society28.1(2008):7-9.
15. Iype M, Prasad M, Nair PM, Geetha S, Kailas L. The newborn with seizures a follow up study. Indian pediatr 2008;45:749-52. 